\title{
Captopril: An Overview of Discovery, Development, and Post-marketing Surveillance as an Effective Anti-hypertensive Drug
}

\author{
Babiker M Elhaj ${ }^{1}$, Farah Hamad Farah ${ }^{2}$ and Heyam Saad Ali ${ }^{3 *}$ \\ ${ }^{1}$ Department of Pharmaceutical Sciences, College of Pharmacy and Health Sciences, \\ University of Science and Technology of Fujairah, Fujairah, UAE \\ ${ }^{2}$ Department of Pharmaceutical Sciences, College of Pharmacy and Health Sciences, \\ Ajman University, Ajman, United Arab Emirates and Center of Medical and \\ Bio-allied Health Sciences Research, Ajman University, Ajman, United Arab \\ Emirates \\ ${ }^{3}$ Pharmaceutics Department, Pharmacy College, University of Khartoum, \\ Khartoum, Sudan \\ *Corresponding Author: Heyam Saad Ali, Pharmaceutics Department, Pharmacy \\ College, University of Khartoum, Khartoum, Sudan.
}

Received: January 27, 2021

Published: March 09, 2021

(C) All rights are reserved by Heyam Saad Ali., et al.

\begin{abstract}
Captopril, the first angiotensin-converting enzyme (ACE) inhibitor was discovered through random screening of 2,000 chemical structures, by E. R. Squibb and Sons Pharmaceuticals. Then patented and developed 1980, to the marketed product Capoten. At a daily dose of 400-1000 mg, the drug showed significant anti-hypertensive activity in patients through enhancing plasma rennin activity, decreasing aldosterone in plasma and elimination of ACE activity. Dose was decreased to 50-150 mg/day after drug resistance was recognized in first 200 patients treated with captopril at the initial dose. Captopril pharmacodynamics and pharmacokinetics parameters were established through continuous clinical trials in human subjects. Initial post-marketing study found it safe and effective for treatment of mild hypertension and early cardiac failure. However, recent studies reveal different adverse events in hypertensive patients treated with captopril.
\end{abstract}

Keywords: Captopril; Hypertension; Angiotensin-converting Enzyme (ACE)

\section{Introduction}

Hypertension is a major health issue worldwide, attributing to the global burden of disease (Dzau and Balatbat, 2019) [6]. It is considered the main cause for various cardiovascular disease mortality and morbidity. There are many disease are associated with hypertension such as cardiovascular the and peripheral arterial diseases. (Hu, Shen, and Yu, 2019). Each year, approximately 9.4 million deaths are caused by hypertension and its complications (Lim., et al. 2012) [16]. The expectation magnitude as has been reported, it will approximately reach one billion and half by
2025 (Kearney., et al. 2005) [14]. Currently, beside (ACE) inhibitors, there are several groups of drugs used for hypertension management such as including angiotensin receptor blockers (ARBs), calcium channel blockers and $\beta$-blockers and diuretics (Siddiqi and Shatat, 2019) [2]. A recent study suggests that ACE inhibitors are the most widely used drugs due to their proved higher efficacy and safety (Suchard., et al. 2019) [24].

Regarding the mechanism of Captopril, which is the first ACE inhibitor, (Gan., et al. 2018; Lezama-Martinez., et al. 2018) [9,15] 
have reported that it acts through suppression of renin-angiotensin-aldosterone system (RAAS).

Captopril has a molecule of unique properties regarding its safety and efficacy. Therefore, till present after passing through all processes of discovery, development, and marketing, (Romano and Tatonetti, 2019) [21]. Captopril is under continuous investigations in different patho-physiological conditions. This review highlights all the different approaches and trials conducted during the discovery and development of the dug, which constitute the aim of this work.

\section{Historical background}

Discovery and identification of molecular target

Captopril was produced from "snake venom", and was identified as enzyme that serves the conversion of angiotensin I to, angiotensin II, in 1950s (Erdos, 2006) [8]. Initially, the investigation of the ACE inhibition effect was conducted using peptides' viper's venom from the Brazilian in dog lung (Bakhle, 1968) [2]. but did not succeed in achieving the desired results (Cushman and Ondetti, 1991). Later on, the anti-hypertensive activity has been approved using 60 different compounds followed by clinical studies (Gavras., et al. 1978) [10].

Development: early clinical trials for efficacy and safety

Initially, the efficacy and safety was conducting with twelve hypertensive patients and the dose of captopril was 400-1000 mg daily, exhibited a decrease in blood pressure of all the patients from $(177 \pm 8 / 110 \pm 2$ to $136 \pm 6 / 88 \pm 2 \mathrm{~mm} \mathrm{Hg})$. That was attributed to enhancement in the activity of rennin, and decrease in aldosterone in plasma. Consequently, elimination of ACE activity were observed in all subjects. Small increase plasma potassium and transient febrile reaction in patient were reported as concomitant effects (Gavras., et al. 1978) [10]. Later on reporting on the data of 200 patients treated with captopril for first four years, the group reported the first dose of 400-1000 mg as excessive and caused resistance that was not recognized during first study. Thus, they concluded 50-150 mg/day as sufficient for the management of hypertension in patients (Hoorntje and Donker, 1981) [11]. Further clinical trials reported that treatment with captopril reduced the mortality in left ventricular dysfunction and asymptomatic left ventricular dysfunction patients by $20 \%$ and $29 \%$ respectively (Investigators*, 1992; Pfeffer., et al. 1992) [13,20].
Pharmacodynamics and pharmacokinetics

Captopril has a rich and interesting pharmacodynamics evolutionary history. Since detailed discussion about pharmacodynamic properties of captopril which is the scope of this review, the review of Brogden., et al. should be read for early pharmacodynamics evolution of captopril (Brogden, Todd, and Sorkin, 1988). Brogden., et al. has also reviewed initial studies of pharmacokinetics for captopril. Results showed $70 \%$ of the drug had been absorbed after oral delivery. Maximum blood concentration $\left(\mathrm{C}_{\text {rnax }}\right)$ was found 0.8-0.9 $\mathrm{mg} / \mathrm{L}$ after an oral dose of $100 \mathrm{mg}$. Time to reach $\mathrm{C}_{\text {rnax }}$ was found to be 0.8 to 1 hour (Brogden., et al. 1988) [3].

Studies were also carried for investigating co-administration of captopril with food, showing that simultaneous food intake decreased its bioavailability by 25 to $50 \%$ in healthy subjects (Mäntylä, Männistö, Vuorela, Sundberg, and Ottoila, 1984) [19]. Further studies carried out for captopril and showed that about $30 \%$ of the drug covalently, but reversibly, bound to protein in human blood (Maeda, Tanaka, Kawameta, Komai, and Shindo, 1979) [18]. In healthy subjects the mean volume of distribution at steady state was 0.70 to $0.75 \mathrm{~L} / \mathrm{kg}$ (Duchin, Singhvi, Willard, Migdalof, and McKinstry, 1982) [4].

\section{Post-marketing surveillance}

The participants in the first post-marketing surveillance were 4,124 patients in New Zealand and the results of the study exhibited higher efficacy of captopril. In addition to demonstration of the drug to high safety profile in both mild and early cardiac failure with demonstrated safety (Edwards, Coulter, Beasley, and MacIntosh, 1987) [7]. Furthermore, various studies revealed clearance of proteinuria ( 1 of 100 patients) within 6 months (Sánchez-Borges and González-Aveledo, 2010) [23]. Moreover, there were some severe adverse reactions associated with the frequent use of captopril have been reported such as: nephrotic syndrome, renal insufficiency, renal failure, (1 to 2 of 1000 patients) (Lindle., et al. 2014) [17], reversible Dysgeusia (2 to 4 of 100 patients) (Antunes, Guerrante, Ávila, Lins Mendes, and Fierro, 2016) [1], (Samrein Ahmed., et al. 2020) [25].

\section{Conclusion}

In conclusion, E. R. Squibb and Sons Pharmaceuticals was the first company that discovered and developed captopril which has potential anti-hypertensive activity. 


\section{Bibliography}

1. Antunes A M d S., et al. "Case study of patents related to captopril, Squibb's first blockbuster". Expert Opinion on Therapeutic Patents 26.12 (2016): 1449-1457.

2. Bakhle Y. "Conversion of angiotensin I to angiotensin II by cellfree extracts of dog lung”. Nature 220.5170 (1968): 919-921.

3. Brogden R N., et al. “Captopril”. Drugs 36.5 (1988): 540-600.

4. Cushman D W and Ondetti M A. "History of the design of captopril and related inhibitors of angiotensin converting enzyme". Hypertension 17.4 (1991): 589-592.

5. Duchin K L., et al. "Captopril kinetics". Clinical Pharmacology and Therapeutics 31.4 (1982): 452-458.

6. Dzau V J and Balatbat CA. "Future of Hypertension: The Need for Transformation". Hypertension 74.3 (2019): 450-457.

7. Edwards I., et al. "Captopril: 4 years of post marketing surveillance of all patients in New Zealand". British Journal of Clinical Pharmacology 23.5 (1987): 529-536.

8. Erdos E G. "The ACE and I: how ACE inhibitors came to be". The FASEB Journal 20.8 (2006): 1034-1038.

9. Gan Z., et al. "Captopril alleviates hypertension-induced renal damage, inflammation, and NF-кB activation". Brazilian Journal of Medical and Biological Research 51.11 (2018).

10. Gavras H., et al. "Antihypertensive effect of the oral angiotensin converting-enzyme inhibitor SQ 14225 in man". New England Journal of Medicine 298.18 (1978): 991-995.

11. Hoorntje S and Donker A. "Clinical use of captopril". Hypertension 3.4 (1981): 507-508.

12. Hu K., et al. "Prevalence and Challenges of Hypertensive Heart Diseases in the Real World". International Journal of Hypertension (2019).

13. Investigators S. "Effect of enalapril on mortality and the development of heart failure in asymptomatic patients with reduced left ventricular ejection fractions". New England Journal of Medicine 327.10 (1992): 685-691.

14. Kearney P M., et al. "Global burden of hypertension: analysis of worldwide data". The Lancet 365.9455 (2005): 217-223.
15. Lezama-Martinez D., et al. "Combined Antihypertensive Therapies That Increase Expression of Cardioprotective Biomarkers Associated With the Renin-Angiotensin and Kallikrein-Kinin Systems". Journal of Cardiovascular Pharmacology 72.6 (2018): 291-295.

16. Lim S S., et al. "A comparative risk assessment of burden of disease and injury attributable to 67 risk factors and risk factor clusters in 21 regions, 1990-2010: a systematic analysis for the Global Burden of Disease Study 2010". The Lancet 380.9859 (2012) 2224-2260.

17. Lindle K A., et al. "Angiotensin-converting enzyme inhibitor nephrotoxicity in neonates with cardiac disease". Pediatric Cardiology 35.3 (2014): 499-506.

18. Maeda T., et al. "Studies on the metabolism of a new antihypertensive agent, SQ 14225 (captopril). I. Paper presented at the vitro studies on the binding to plasma protein and behavior in blood". In: Proceedings of the 99th Annual Meeting of the Pharmaceutical Society of Japan, Sapporo, August (1979).

19. Mäntylä R., et al. "Impairment of captopril bioavailability by concomitant food and antacid intake". International Journal of Clinical Pharmacology, Therapy, and Toxicology 22.11 (1984): 626-629.

20. Pfeffer M A., et al. "Effect of captopril on mortality and morbidity in patients with left ventricular dysfunction after myocardial infarction: results of the Survival and Ventricular Enlargement Trial". New England Journal of Medicine 327.10 (1992): 669-677.

21. Romano J D and Tatonetti N P. "Informatics and computational methods in natural product drug discovery: a review and perspectives". Frontiers in Genetics 10 (2019): 368.

22. Sánchez-Borges M., et al. "Angiotensin-converting enzyme inhibitors and angioedema". Allergy, Asthma and Immunology Research 2.3 (2010): 195-198.

23. Siddiqi N and Shatat IF. "Antihypertensive agents: a long way to safe drug prescribing in children". Pediatric Nephrology (2019): $1-17$.

24. Suchard M A., et al. "Comprehensive comparative effectiveness and safety of first-line antihypertensive drug classes: a system- 
atic, multinational, large-scale analysis". The Lancet 394.10211

(2019): 1816-1826.

25. Samrein Ahmed., et al. "Assessing the knowledge of environmental risk factors for cancer among the UAE population: A pilot study". International Journal of Environmental Research and Public Health 17.9 (2020): 2984.

\section{Assets from publication with us}

- Prompt Acknowledgement after receiving the article

- Thorough Double blinded peer review

- Rapid Publication

- Issue of Publication Certificate

- High visibility of your Published work

Website: www.actascientific.com/

Submit Article: www.actascientific.com/submission.php

Email us: editor@actascientific.com

Contact us: +919182824667 